\title{
Charging electric vehicles from photovoltaic generation with intermediate energy storage
}

\author{
Carlos Silva*, Duarte M. Sousa**, and António Roque*** \\ *Instituto Superior Técnico - Universidade de Lisboa, Portugal \\ **Instituto Superior Técnico \& INESC-ID - Universidade de Lisboa, Portugal \\ ***ESTSetúbal - Instituto Politécnico de Setúbal \& INESC-ID, Portugal
}

\begin{abstract}
The consumption of fossil fuels on a large scale and the environmental problems resulting from the emission of polluting gases into the atmosphere, created the need for change in mobility habits in today's daily life. Responding to these new challenges, strong investments have been made by companies and governments in the automotive sector being the development of electric vehicles and the technologies associated with them an assumed priority by all the stakeholders. Fast charging of batteries is one of the technical issues that have been addressed. In addition, fast charging of electric vehicles in remote locations can be implemented taking advantage of renewable energy systems and avoiding power demand from conventional power grids. In this paper, the power can be supplied by a photovoltaic generation system and is managed taking advantage of an intermediate energy storage system based on a battery bank and supercapacitors. The operation of the proposed system is observed performing simulations conditions, which allow checking the correct operation of the system and its response to possible failures of the subsystems that constitute it.
\end{abstract}

Index Terms-- Isolated location; Fast charging; Single phase electric grid; Photovoltaic power generation system; Intermediate energy storage system; Power flow.

\section{INTRODUCTION}

Coming back to the industrial revolution, it represents one of the key moments in the development of means of transport, since it is a result of this that appear the main engines used by today automobile industry: the internal combustion engine and the electric motor.

Among other solutions, electric vehicles (EVs) are presented as one of the best solutions to address the problems of dependence on fossil fuels, the release of high levels of carbon dioxide and other gases to the atmosphere responsible for increasing the greenhouse effect and depletion of the ozone layer [1]. These vehicles began to gradually rise again in the $90 \mathrm{~s}$, a time where record values were verified for the price of oil, which led to the start of a strong investment in exploration of energy production from renewable sources and the development of technologies used by EVs, with special emphasis on the batteries [2-4].

This work was supported by national funds through Instituto Politécnico de Setúbal and Fundação para a Ciência e a Tecnologia (FCT) with reference UID/CEC/50021/2013.

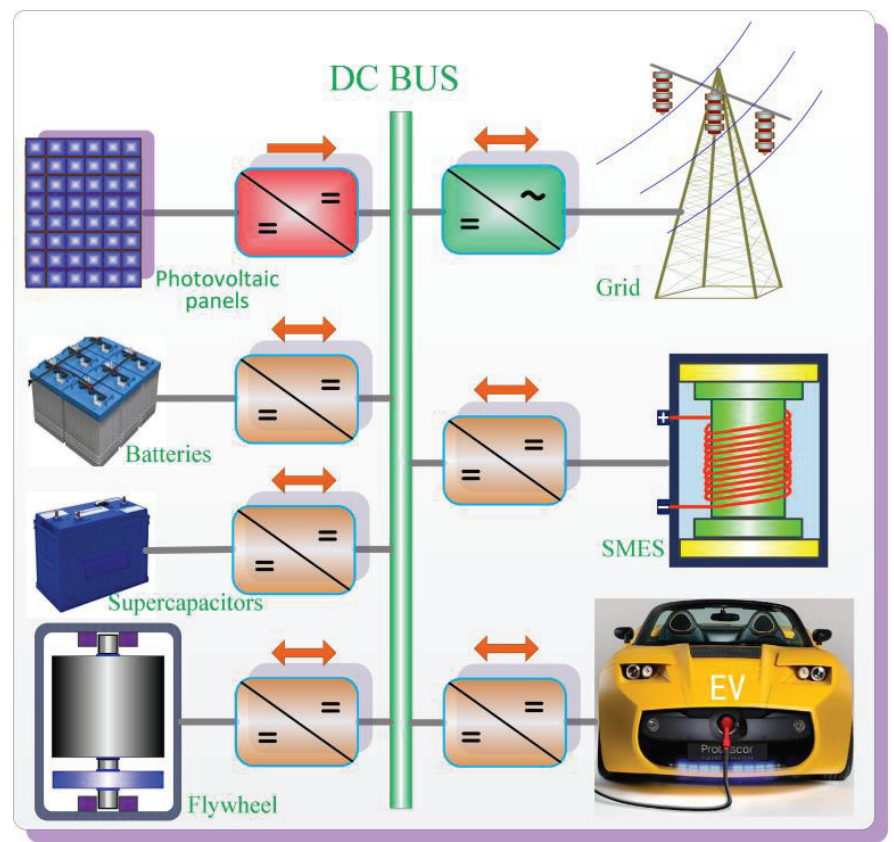

Fig. 1. General scheme of the power system.

Currently it is possible to separate the charging of EVs into three major groups, taking into account the battery charging times [5]:

- Slow Charging: the charging of the EV is made through monophasic alternate current (AC) sockets similar to domestic ones and the charging takes between $6 \mathrm{~h}-8 \mathrm{~h}$.

- Semi-Fast Charging: AC charging mode taking between $1 \mathrm{~h}-1.5 \mathrm{~h}$ to charge the EV batteries and usually uses three-phase outlets that can be found in public spaces.

- Fast Charging: is characterized by using direct current (DC) and is capable of charging $80 \%$ of the capacity of the EV batteries in a period of 10 to 30 minutes.

The development and installation of a large number of Fast Charging Electric Vehicle Stations (FCEVS) is the next step of the electric mobility needs to move forward full mobility of EV users [4],[6-9].

Taking as example the Portuguese case, the charging network has been increasing over the last few years having at this point 1300 normal charging stations and 50 fast charging stations, which make it possible to travel crossing the country from north to south using EVs. 
Although the number of EVs in circulation today does not strongly press the installation of charging stations in many urban sites, it becomes a reality day after day. For other hand, regarding remote places, the picture is slightly different.

Considering a remote location, in this paper, a model to a fast charging electric vehicle system using different subsystems of power generation and an intermediate energy storage system is considered. This system is analyzed simulating the solution under different operation conditions, for which are observed the response of the different sub-systems.

\section{SYSTEM DESCRIPTION}

A fast charging electric vehicle system can be composed by a DC bus and following subsystems [2]:

- Generation and supply:

- a Photovoltaic Power Generation System (PV);

- a grid connection system.

- Storage:

- an Energy Storage System (ESS);

- a superconducting magnetic energy storage (SMES);

- a flywheel (FW).

- Load:

- a Charging System (CS).

The general scheme of the proposed system is presented in Figure 1.

At this stage, the fast charging system is analysed neglecting the contribution of SMES and of the FW being described the operation and presented the main characteristics of the other sub-systems.

\section{A. Energy Storage Systems}

To store energy, the proposed solution combines a bank of Lead-Acid batteries and supercapacitors (SC) taking advantage of the high specific energy value of the batteries and the high value of specific power of a SC [10-13].

The use of an intermediate energy storage system allows, as important feature, to decrease the power demand from the generation and supply systems. In particular, when charging an EV, it is possible to compensate great power demands and current peaks from the single-phase network, for instance, which when occurring can unbalance and stop the charging process.

The SC are connected to the DC bus through a buck/boost converter, which not only allows the transfer of energy into the DC bus, but also in the opposite way if it is necessary to absorb energy, as for instance, when current peaks are observed [14-16]. Since the battery bank acts as an auxiliary ESS to the SC, it is used a boost converter to link the battery bank and the DC bus allowing the energy transit towards the DC bus.

The battery bank is based on Lead-Acid batteries connected in series with the parameters presented in the Table I.
TABLE I

PARAMETERS OF THE BATTERY BANK

\begin{tabular}{|l|l|l|}
\hline \multicolumn{2}{|l|}{ Parameters } & Value \\
\hline & Number of batteries & 20 \\
\hline $\mathrm{V}_{\mathrm{N}(\mathrm{BAT})}$ & Nominal Voltage & $240 \mathrm{~V}$ \\
\hline $\mathrm{C}_{\mathrm{N}(\mathrm{BAT})}$ & Nominal Capacity & $105 \mathrm{Ah}$ \\
\hline $\mathrm{I}_{\mathrm{N}(\mathrm{BAT})}$ & Nominal Discharge Current & $21 \mathrm{~A}$ \\
\hline $\mathrm{R}_{\mathrm{INT}}$ & Internal Resistance & $5 \mathrm{~m} \Omega$ \\
\hline $\mathrm{V}_{\mathrm{BAT}(\max )}$ & Maximum Voltage & $264 \mathrm{~V}$ \\
\hline $\mathrm{C}_{\mathrm{BAT}(\max )}$ & Maximum Capacity & $105 \mathrm{Ah}$ \\
\hline
\end{tabular}

The circuit used to simulate the battery bank and the boost converter system is shown in Fig. 2 .

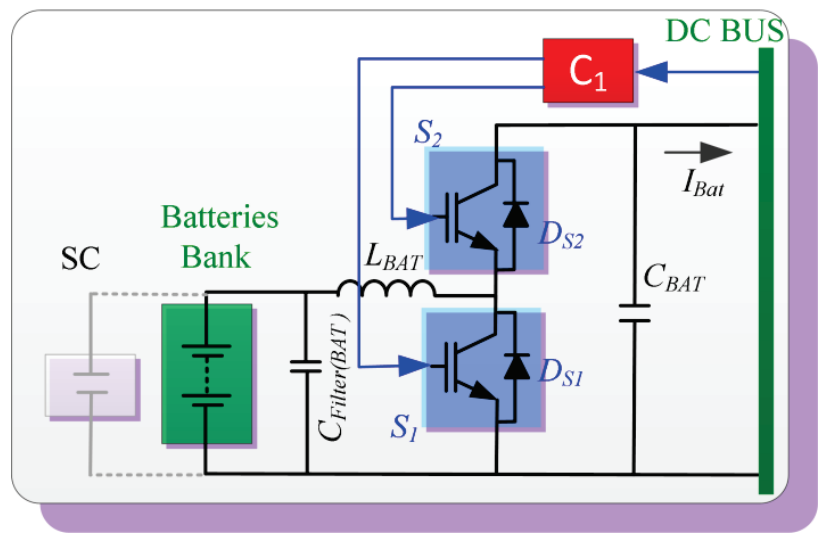

Fig. 2. Buck-boost bi-directional converter associated to the battery bank.

Being the battery bank connected to the DC/DC boost converter, it elevates the $V_{B A T}$ to a value of $400 \mathrm{~V}$. In order to ensure that the voltage fluctuations are below $10 \%$ of this value it is necessary to implement a voltage control system.

To simulate the SC storage system are used as reference the parameters of a single supercapacitor presented in Table II.

TABLE II

PARAMETERS OF THE SUPERCAPACITOR

\begin{tabular}{|l|l|l|}
\hline \multicolumn{2}{|l|}{ Parameters } & Value \\
\hline$C_{N(S C)}$ & Nominal Capacity & $5.8 \mathrm{~F}$ \\
\hline$V_{N(S C)}$ & Nominal Voltage & $160 \mathrm{~V}$ \\
\hline$I_{N(S C)}$ & Nominal Current & $35 \mathrm{~A}$ \\
\hline$E S R$ & Equivalent Series Resistance & $240 \mathrm{~m} \Omega$ \\
\hline \multicolumn{1}{|c|}{$\tau$} & Lifetime (High Temperatures) & $1500 \mathrm{~h}$ \\
\hline
\end{tabular}

The circuit used to simulate the SC system and the buck/boost converter system is similar to the topology shown in Fig. 2.

The buck/boost DC/DC converter used in this case also requires a voltage control system to maintain the $V_{D C}$ around $400 \mathrm{~V}$.

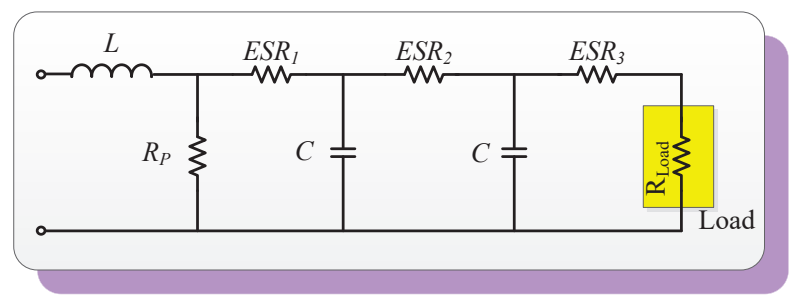

Fig. 3. Equivalent electric circuit of a supercapacitor. 
In order to simulate the operation of the supercapacitors in a more realistic way, the model represented in Fig. 3 is used [17].

The model presented in Fig. 3 takes into account the non-linear behaviour of the SCs. The three equivalent series resistances $\left(E S R_{i}\right)$ correspond to the representation of the physical system (the two electrodes and the dielectric), while the value of the resistor $R_{P}$ is determined taking into account the time constant ( $\tau=R_{p} C$ ) of an RC circuit.

\section{B. Photovoltaic Power Generation Systems}

The photovoltaic power generation system consists of an array of PVs, connected in series and in parallel, which are working at its maximum power point due to the operation of a Maximum Power Point Tracking (MPPT) system developed, which is presented in Fig. 4 [18-21].

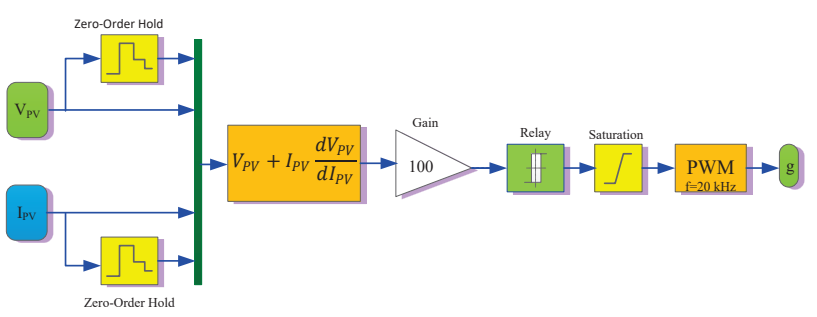

Fig. 4. MPPT system used by the PV panel.

The PV equivalent characteristics resulting from $8 \mathrm{PV}$ panels associated in series and 5 in parallel, which accounts for a total of $56.25 \mathrm{~m}^{2}$ are shown in Table III.

TABLE III

CHARACTERISTICS OF THE EQUIVALENT PV PANEL

\begin{tabular}{|l|l|}
\hline Parameters & Value \\
\hline$P_{M A X}$ & $7601.04 \mathrm{~W}$ \\
\hline$V_{M P}$ & $194.4 \mathrm{~V}$ \\
\hline$I_{M P}$ & $39.1 \mathrm{~A}$ \\
\hline$V_{O C}$ & $244.8 \mathrm{~V}$ \\
\hline$I_{S C}$ & $42.5 \mathrm{~A}$ \\
\hline$N_{S}$ & $400 \mathrm{cells}$ \\
\hline Length & $13.44 \mathrm{~m}$ \\
\hline Width & $4.185 \mathrm{~m}$ \\
\hline Weight & $639 \mathrm{~kg}$ \\
\hline
\end{tabular}

Assuming that the behaviour of the individual modules is maintained when these are connected in series or parallel, thus, the series connected modules are responsible for increasing the voltage available at the output of the PV, while the modules connected in parallel increases the current available.

As mentioned above, the connection between the photovoltaic panels and the DC bus is made through a DC/DC converter, which is composed by "two levels". The circuit model used to simulate this sub-system is shown in Fig. 5.

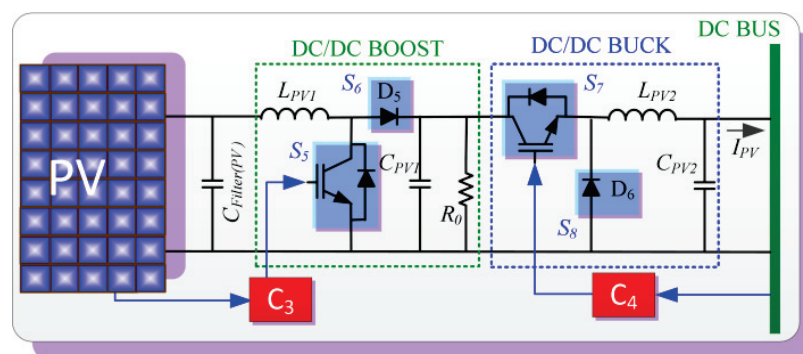

Fig. 5. Converter associated to the photovoltaic system.

As can be seen in Fig. 5, the first level consists in a boost converter which is controlled by the MPPT system and extract the maximum power possible from the PV panel and elevates its output voltage. The second one is composed by a buck converter controlled by the voltage control system and that is responsible to reduce the power provided by the first level and maintain $V_{D C}$ around $400 \mathrm{~V}$.

\section{Charging System}

The EVs charging system is responsible for the connection between the DC bus and the batteries bank of the vehicle connected to the charging system. This system is based on a bi-directional buck-boost DC/DC converter to allowing energy transit towards the EV (Grid-toVehicle - G2V), working as a buck converter, or towards the DC bus (Vehicle-to-Grid - V2G), working as a boost converter. The option to use this type of converter is due to the use of a smaller number of semiconductors by comparison, for example, with a DC/DC Dual Active Bridge converter or a DC/DC 3 level buck/boost converter.

To simulate this system it is used the data corresponding to a Lithium- Ion type battery, which parameters are presented in Table IV.

TABLE IV

PARAMETERS USED FOR THE EV BATTERY

\begin{tabular}{|l|l|l|}
\hline \multicolumn{2}{|l|}{ Parameters } & Value \\
\hline & Battery Type & Lithium-Ion \\
\hline$V_{N(E V)}$ & Nominal Voltage & $360 \mathrm{~V}$ \\
\hline$C_{N(E V)}$ & Nominal Capacity & $66.6 \mathrm{Ah}$ \\
\hline$I_{N(E V)}$ & $\begin{array}{l}\text { Nominal Discharge } \\
\text { Capacity }\end{array}$ & $28.9 \mathrm{~A}$ \\
\hline$R_{I N T}$ & Internal Resistance & $0.054 \Omega$ \\
\hline
\end{tabular}

The circuit model used to simulate the charging system is shown in Fig. 6.

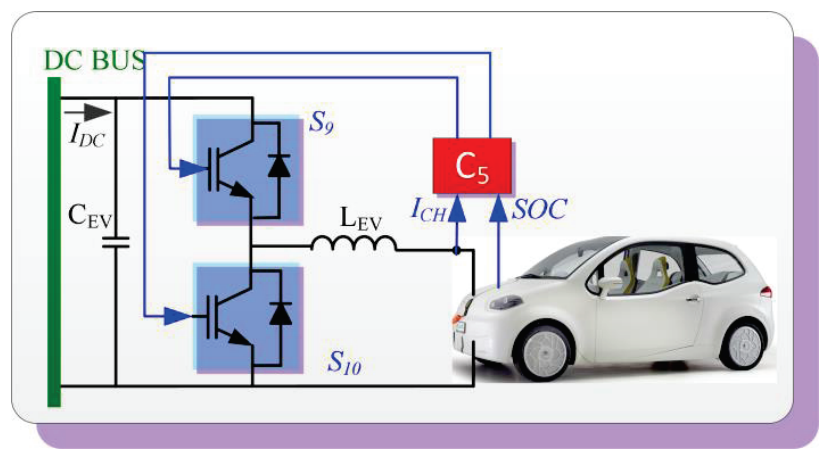

Fig. 6. Converter associated to the charging system. 
Along with the converter is designed a control system to determine the operating mode of the charging system, depending on the State- Of-Charge (SOC) of the EV battery connected to the system.

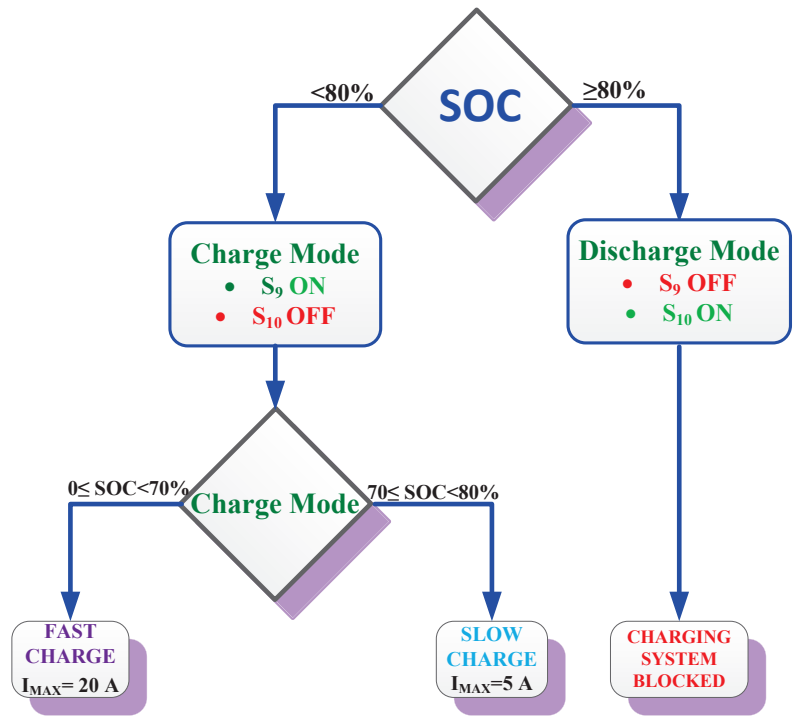

Fig. 7. Flowchart of the decisions used to control the charging system.

Essentially when an EV is connected to the fast charging system, the control system check the SOC of the EV battery, in order to decide whether to start the charge (SOC $<80 \%$ ) or the discharge mode (SOC $\geq 80 \%$ ). In case the charge mode is activated, the control system carries a second check to verify if should activate the fast charge $(0 \% \leq \mathrm{SOC}<70 \%)$, which is characterized by a charging current of $20 \mathrm{~A}$, or the slow charge $(70 \% \leq \mathrm{SOC}<80 \%)$, which uses a charging current of 5 A. In Fig. 7 is presented the flowchart for controlling the charge/discharge process.

\section{Grid Connection}

In the developed model, the connection to the monophasic grid is made through a full wave diode rectifier, which implies that the power only flows from the electric network to the system, and therefore, it is not possible to inject power into the grid (Fig. 8) [22-23]. In general this connection is bi-directional but in the present study only this feature was considered since the AC grid is considered the ultimate power source satisfying the power needs of the charging system.

Besides the rectifier, there is also used a low frequency transformer $\left(\mathrm{T}_{1}\right)$ which ensures the galvanic isolation of the system, the adaptation of the rectifier input voltage level and the elimination of the continuous components present in the rectifier input currents, considering the electric network point of view [24].

So that, the characteristics of the transformer used to analyse the proposed system are summarized in Table V.

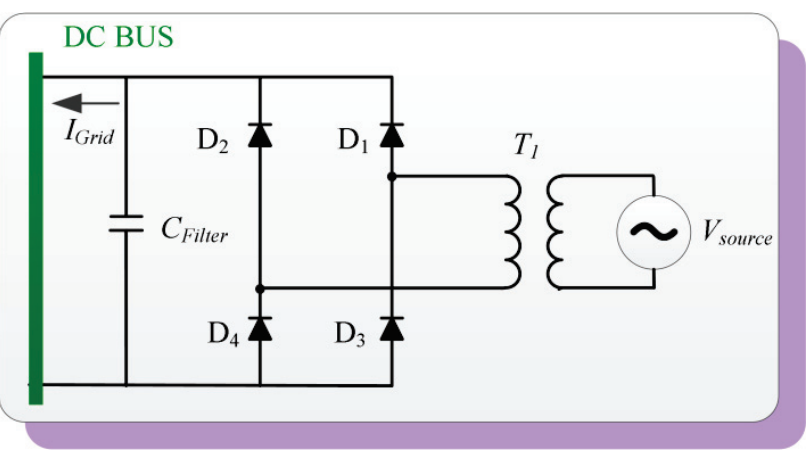

Fig. 8. Grid to DC bus connection.

TABLE V

TRANSFORMER CHARACTERISTICS

\begin{tabular}{|l|l|l|}
\hline \multicolumn{2}{|l|}{ Parameters } & Value \\
\hline$S_{N}$ & Nominal apparent power & $30 \mathrm{kVA}$ \\
\hline$f_{N}$ & Nominal frequency & $50 \mathrm{~Hz}$ \\
\hline$V_{l} / V_{2}$ & Voltages & $230 / 450 \mathrm{~V}$ \\
\hline$R_{m}$ & Magnetization resistance & $881.67 \Omega$ \\
\hline$L_{m}$ & Magnetization inductance & $2.8064 \mathrm{H}$ \\
\hline
\end{tabular}

\section{Simulation RESUltS}

The fast charging system can be analysed considering different scenarios. In this section are presented the results obtained under the following conditions:

i) Initially all the subsystems are in normal operation and at the instant $t=0.25 \mathrm{~s}$ the ESS is switched off, stopping to supply power to the system;

ii) The initial SOC of the battery $\mathrm{EV}$ is: SOC $_{\text {Initial }}=69.9 \%$.

iii) The equivalent load at the DC bus is: RL Load $\rightarrow \mathrm{R}=250 \Omega$ and $\mathrm{L}=2 \mathrm{mH}$.

This scenario allows to check the response of the charging system to the "failure" of one of his subsystems and, due to the initial SOC chosen to the EV battery, it is possible to check the robustness of the control system.

In Fig. 9, it can be seen the evolution of the EV battery SOC between $69.996 \%$ and $70.001 \%$, illustrating the change between charging modes, as the Fig. 7 flowchart. For the period illustrated, during the charging are observed two charging modes: the fast charge mode for a SOC below $70 \%$, which is reached at $\mathrm{t}=0.587 \mathrm{~s}$, and after that the slow charge mode $(70 \%<\mathrm{SOC}<80 \%)$. Due to the lower value of current imposed in the slow charge mode, it is verified that the "speed" of charge of the EV battery slows down, as expected.

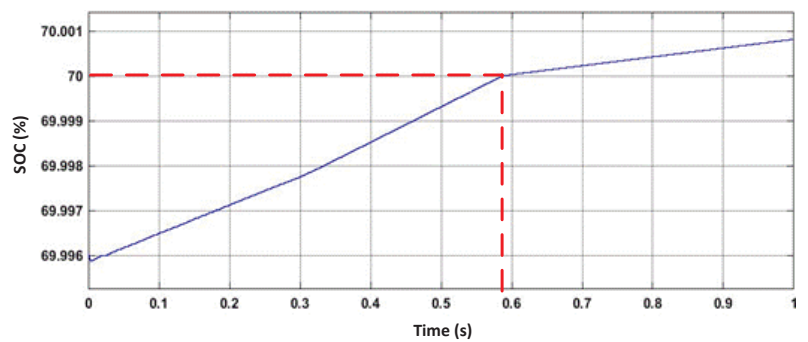

Fig. 9. Evolution of EV battery SOC during the charging.

As described above, the ESS is switched off at 
$t=0.25 \mathrm{~s}$ not supplying power to the DC bus after this instant as it can be confirmed by the output current of the ESS $\left(I_{E S S}=I_{S C}+I_{B a t}\right)$ in Fig. 10, joining the contributions of the battery $\left(I_{B a t}\right)$ and of the supercapacitor $\left(I_{S C}\right)$.

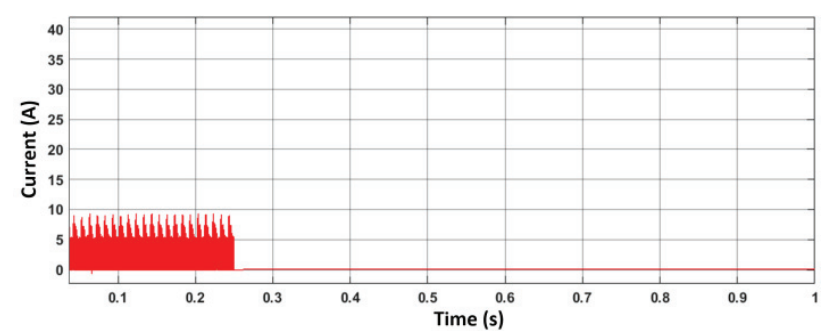

Fig. 10. Output current of the EES system.

The current in the DC BUS $\left(I_{D C}\right)$ for charging the EV results from the contribution of the current $I_{E S S}$, with the current of the photovoltaic system $\left(I_{P V}\right)$. In Fig. 11, it is possible to observe that after the shutdown of the ESS $(t=0.25 \mathrm{~s})$, there is an increase of the value of $I_{P V}$, to compensate the existing failure. It is also possible to verify that after the change to the slow charge mode $I_{P V}$ decreases from $20 \mathrm{~A}$ to $5 \mathrm{~A}$ in accordance with the current levels defined.

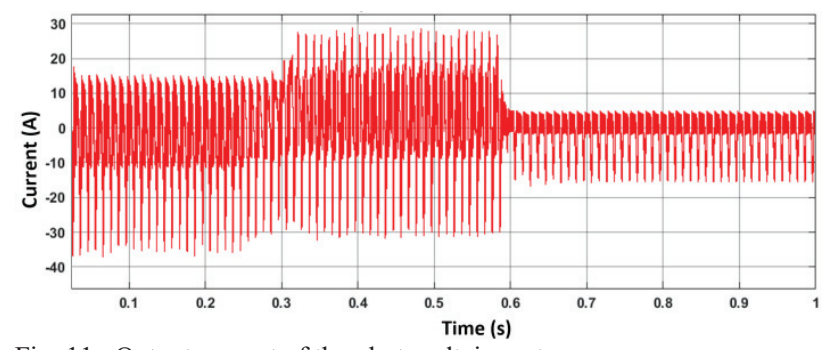

Fig. 11. Output current of the photovoltaic system.

In order to observe the behaviour of the system for different operation conditions, in Fig. 12 is shown the DC bus voltage.

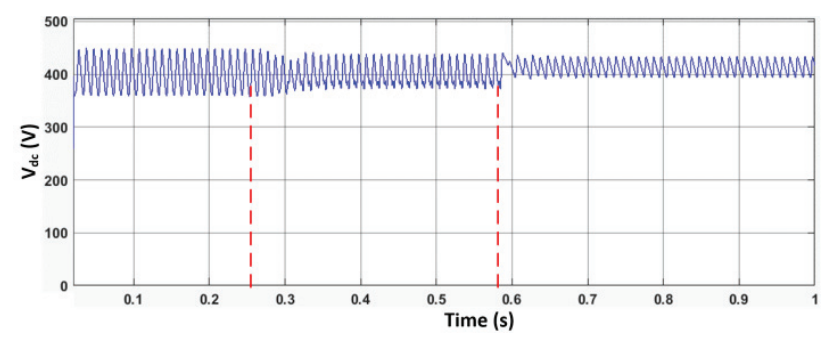

Fig. 12. DC bus voltage.

During the simulation, $V_{D C}$ oscillates, as desired, around the value of $400 \mathrm{~V}$, as a result of the action of the voltage control system.

\section{CONCLUSIONS}

This paper proposes a fast charging system to be installed in remote locations, which uses multiple power supplies and an intermediate energy storage system. The proposed charging system performs the charging of the batteries of the EVs through a DC/DC converter that makes the link between the EV and a DC bus, which is held around $400 \mathrm{~V}$ through a control system of the output voltage of each subsystems that provide power: a photovoltaic generation system and an energy storage system (consisting of a batteries and supercapacitors).

Through the performed simulations it can be concluded that the system is operating using the ESS as an equilibrium point, preventing current peaks and contributing to the efficiency of the charging process.

\section{REFERENCES}

[1] C. C. Chan, "The state of the art of electric, hybrid, and fuel cell vehicles," Proc. IEEE, vol. 95, no. 4, pp. 704718, 2007.

[2] L. Dickerman and J. Harrison, "A New Car, a New Grid," IEEE Power Energy Mag., vol. 8, no. 2, pp. 55-61, 2010.

[3] Y. Segura, L. Chmielarz, P. Kustrowski, P. Cool, R. Dziembaj, and E. Vansant, "Preparation and characterization of vanadium oxide deposited on thermally stable mesoporous titania," J. Phys. Chem. B, vol. 110, no. 2, pp. 948-955, 2006.

[4] A. Yilmaz, M. Badawi, Y. Sozer, and I. Husain, "A fast battery charger topology for charging of electric vehicles," IEEE Int. Electr. Veh. Conf. (IEVC), 2012.

[5] M. Yilmaz and P. T. Krein, "Review of charging power levels and infrastructure for plug-in electric and hybrid vehicles," IEEE Int. Electr. Veh. Conf. (IEVC), 2012.

[6] S. Bai, Y. Du, and S. Lukic, "Optimum design of an EV/PHEV charging station with DC bus and storage system," IEEE Energy Convers. Congr. Expo. (ECCE), pp. 1178-1184, 2010.

[7] S. Dusmez, A. Cook, and A. Khaligh, "Comprehensive analysis of high quality power converters for level 3 offboard chargers," IEEE Veh. Power Propuls. Conf. (VPPC), pp. 1-10, 2011.

[8] D. Christen, F. Jauch , J. Biela, "Ultra-Fast Charging Station for Electric Vehicles with integrated split Grid Storage,", 17th Eur. Conf. Power Electron. Appl. (EPE'15 ECCE-Europe), pp. 1-11, 2015.

[9] G. Joos, M. De Freige, and M. Dubois, "Design and simulation of a fast charging station for $\mathrm{PHEV} / \mathrm{EV}$ batteries," EPEC 2010 - IEEE Electr. Power Energy Conf. Sustainable Energy an Intell. Grid, 2010.

[10] T. B. Reddy, Handbook of Batteries, McGraw-Hill Library, 2002.

[11] M. Glavin, P. Chan, S. Armstrong and W. Hurley, "A stand-alone photovoltaic supercapacitor battery hybrid energy storage system," 13th EPE-PEMC - Power Electronics and Motion Control Conference, pp. 1688$1695,2008$.

[12] T. A. Singo, A. Martinez and S. Saadate, "Using ultracapacitors to optimize energy storage in a photovoltaic system," Int. Symp. Power Electronics, Electrical Drives, Automation and Motion (SPEEDAM), pp. 229-234, 2008.

[13] W. Li and G. Joos, "A power electronic interface for a battery supercapacitor hybrid energy storage system for wind applications," IEEE Power Electronics Specialists Conference (PESC), pp. 1762-1768, 2008.

[14] C. Zhao, S. D. Round, and J. W. Kolar, "An isolated threeport bidirectional dc-dc converter with decoupled power flow management," IEEE Trans. Power Electron., vol. 23, no. 5, pp. 2443-2453, 2008.

[15] J. Harper, "Development and Implementation of SAE DC Charging Digital Communication for Plug-in Electric Vehicle DC Charging," SAE Technical Paper 2013-011188, 2013. 
[16] G. Oggier, L. Botalla, and G. García, "Soft-switching analysis for three-port bidirectional DC-DC converters," 9th IEEE/IAS Int. Conf. Ind. Appl. (INDUSCON), 2010.

[17] M. Harfman-Todorovic, M. Chellappan, L. Palma and P. Enjeti, "The role of supercapacitors in designing fuel cell powered portable applications," IEEE Power Electronics Specialists Conference, pp. 2465-2472, June 2008.

[18] R. Faranda, S. Leva, and V. Maugeri, "MPPT techniques for PV systems: Energetic and cost comparison," IEEE Power and Energy Society General Meeting - Conversion and Delivery of Electrical Energy in the 21st Century, pp. $1-6,2008$.

[19] T. Esram and P. L. Chapman, "Comparison of Photovoltaic Array Maximum Power Point Tracking Techniques," IEEE Trans. Energy Convers., vol. 22, no. 2, pp. 439-449, 2007.

[20] J. Enslin, M. Wolf, D. Snyman and W. Swiegers, "Integrated photovoltaic maximum power point tracking converter," IEEE Transactions on Industrial Electronics, vol.44, pp. 769 - 773, Issue: 6, 1997.

[21] T. Shimizu, M. Hirakata, T. Kamezawa and H. Watanabe, "Generation control circuit for photovoltaic modules," IEEE Transactions on Power Electronics, Vol. 16, pp. 293 - 300, Issue: 3, May 2001.

[22] K. Yunes, H. Z. De La Parra e M. Reza, "Distribution grid impact of plug-in electric vehicles charging at fast charging stations using stochastic charging model," Proc. 2011 14th Eur. Conf. Power Electron. Appl., pp. 1-11, 2011.

[23] J. Subjak and J. McQuilkin, "Harmonics-Causes, effects, measurements, and analysis: an update," IEEE Trans. Ind. Appl., vol. 26, no. 6, pp. 1034-1042, 1990.

[24] P. Cheng, S. Yang, Y. Guan, and S. Wang, "Design and Implementation of coaxial Winding Transformers for Isolated DC-DC Converters," IEEE Power Convers. Conf. (PCC), Nagoya, pp. 1-8, 2007. 